\title{
Impact of Using Simulation on Critical Care Nursing Students' Knowledge and Skills of Acute Respiratory Distress Syndrome
}

\author{
Fayza Ahmed Abdou ${ }^{1}$, Rawhia Salah Dogham ${ }^{2}$ \\ 1(Critical care nursing department, Faculty of nursing, Assuit University) \\ ${ }_{2}^{2}$ (Nursing education department, Faculty of nursing, Alexandria University)
}

\begin{abstract}
Acute respiratory distress syndrome is common in critically ill patients admitted to intensive care units. Simulation, the art and science of recreating a clinical scenario in an artificial setting, has been an important aspect of nursing program curriculums for decades. Aim: to determine the impact of using simulation on critical care nursing students' knowledge and skills of acute respiratory distress syndrome. Design: quasi experimental research design. Setting: critical care lab in faculty of nursing at Assuit University. Methods: sixty critical care nursing students were included in this study. Acute respiratory distress syndrome assessment questioners, performance checklist about acute respiratory distress syndrome and student satisfaction questionnaire have been used. The study was carried out on four phases: assessment, preparation, implementation and evaluation. Results: There was a statistical significant difference between the control and the study group after using the simulation strategy in relation to their knowledge and clinical performance of Acute Respiratory Distress Syndrome. Conclusion: The level of critical care nursing students' knowledge and clinical performance of Acute Respiratory Distress Syndrome were general improved after application of teaching program with simulation learning strategy.
\end{abstract}

Key words: ARDS, simulation, critical care nursing, knowledge, performance

\section{Introduction}

Acute respiratory distress syndrome (ARDS) is a common in critically ill patients admitted to intensive care units (ICU). ARDS results in increased use of critical care resources and healthcare costs, yet the overall mortality associated with these conditions remains high ${ }^{(1)}$. Mortality usually results from multi-system organ failure due to the lack of oxygen, rather than lung failure alone. The acute respiratory distress syndrome is the sudden acute onset, bilateral, inflammatory pulmonary infiltrates and impaired oxygenation It is the extreme end of a continuum of hypoxic acute lung injury (ALI) that results in respiratory failure. It can be life- threatening because normal gas exchange does not take place due to severe fluid buildup in both lungs ${ }^{(1,2)}$.

ARDS is caused mainly by extensive lung inflammation and small blood vessel injury due to sepsis (bacterial infection of the blood), trauma and/or severe pulmonary infection such as pneumonia. However, ARDS also can be linked to multiple transfusions, inhalation of salt water, smoke inhalation of toxic chemicals, aspiration of vomit (inhaling vomit into the lungs), narcotics, sedatives, overdoses of tricyclic antidepressants and shock from any cause. The condition is characterized by rapid breathing, difficulty getting enough air into the lungs and low blood oxygen levels ${ }^{(1)}$.

Early signs and symptoms of respiratory distress include tachypnea, dyspnea, and tachycardia. Patients with acute respiratory failure may exhibit neurological changes, such as restlessness and agitation associated with impaired oxygenation and decreased perfusion to the brain ${ }^{(1,2)}$. Use of accessory respiratory muscles is evident. As the pathological changes progress, lung auscultation may reveal crackles secondary to an increase in secretions and narrowed airways; however, the bubbling crackles of cardiogenic pulmonary edema may be minimal. Other later stages of progression result from tissue hypoxia and include dysrhythmias, chest pain, decreased renal function, and decreased bowel sounds. These are indications of multisystem involvement as highly perfused organ systems respond to decreased oxygen delivery with diminished function. Research focusing on preventing ARDS and identifying patients at risk of developing ARDS is necessary to develop strategies to alter the clinical course and progression of the disease ${ }^{(3)}$.

Medical management of ARDS involves supportive care in an intensive care unit. It consists of supplemental oxygen and mechanical ventilation along with careful attention to fluid balance and a supportive breathing technique called positive end expiratory pressure (PEEP). These are combined with continuing treatment of the underlying illness or injury. In addition, extensive work has gone into creating "bundles," which are elements of care considered core to the management and treatment of specific critical illnesses in intensive care units (ICUs). The essential critical care bundles that apply to managing ARDS such as ventilator associated pneumonia , sepsis and other protocols that may be added such as tight glucose control, post pyloric feeding, subglottic suctioning and electrolyte replacement. Regardless, one of the most important roles for critical care nurses is ensuring attention to all these elements to prevent mortality and to promote recovery ${ }^{(1,3,4)}$. 
Important the alarming rise in morbidity and mortality among critically ill patients suffering from ARDS heightens concerns about professional competency ${ }^{(4)}$. Nursing education is unique in that it demands a smaller instructor to student ratio during clinical rotations, when students actually apply their knowledge obtained through lectures and implement the nursing process in actual practice with human patients. Unfortunately, this nursing faculty shortage translates to an increased instructor-to-student ratio on the clinical units. This allows little time for students to develop critical thinking skills and practice clinical decision-making with appropriate faculty guidance. Experiential learning theory has been used in health professions education to emphasize the importance of clinical practice in the educational process. It is during this clinical practice that the student has the opportunity to apply abstract concepts learned in the classroom in order to enhance learning and understanding of concepts. With today's changing health care environment, there is no guarantee that the clinical unit will provide the learning opportunities necessary to expose the student to low incidence but highly critical events. The nursing shortage, nursing faculty shortage, and increased ratio of student nurses to clinical faculty on clinical units may jeopardize patient safety ${ }^{(5,6)}$.

Nursing education has long utilized simulation in some form to teach principles and skills of nursing care. Models of anatomic parts, whole body mannequins, and various computer-based learning programs have provided educators with training tools for students seeking to become professional nurses. Current interest in simulation as a clinical teaching tool has largely been fueled by development of the Human Patient Simulation (HPS) ${ }^{(6)}$.

Moderate fidelity simulators give more resemblance of reality with such features as pulse, heart sounds, and breathing sounds but without the ability to talk and they lack chest or eye movement. They can be used for both the introduction and deeper understanding of specific, increasingly complex competencies. Nursing service has used the HPS mostly in the critical care area to teach nurses how to care for the critically ill patient and to test advanced cardiac life support skills. Most recently, HPS is being used in nursing programs with graduate and undergraduate students. In every aspect of patient care, hands-on experience is the best teacher. Use of the HPS as a teaching tool in nursing education can provide a more interactive learning environment for students. Not only can students see a variety of complex case scenarios, they can also practice in a real lifelike situation. The student is able to work in a more controlled environment and is thus able to focus on making clinical judgments regarding clients' problem situations without fear of harm to clients ${ }^{(7)}$.

Human patient simulation is a relatively new teaching strategy that allows learners to develop, refine, and apply knowledge and skills in a realistic clinical situation as they participate in interactive learning experiences designed to meet their educational needs. Learners participate in simulated patient care scenarios within a specific clinical environment, gaining experience, learning and refining skills and developing competencies; all this is accomplished without fear of harm to a live patient. The use of simulation as a teaching strategy can contribute to patient safety and optimize outcomes of care, providing learners with opportunities to experience scenarios and intervene in clinical situations within a safe, supervised setting without posing a risk to a patient ${ }^{(6-8)}$.

Nursing educators are challenged to teach students to think critically, to go beyond simply "knowing," to advance to synthesis and application of knowledge as they assess, plan, implement, and evaluate nursing care $^{(7)}$. Simulation provides an alternative to the traditional teacher-centered approach to nursing education with emphasis on the learning needs and preferences of contemporary nursing students. Simulated learning experiences with the patient simulator allow faculty to expose students to situations that they may never see in their clinical practicum experiences. Because students are placed in a variety of units for their clinical experiences, there is a lack of consistency in learning opportunities across and among students. Use of the patient simulator enables faculty to provide structured simulation lab experiences instead of trying to find appropriate and/or rare patient care opportunities in a health care setting ${ }^{(8)}$.

Aim of the study:

To determine the impact of using simulation on critical care nursing students' knowledge and skills of acute respiratory distress syndrome

\section{Methods}

\section{Research design}

To meet the aim of this study a quasi-experimental research design was selected.

Setting

This study was conducted in critical care nursing lab of Faculty of Nursing at Assuit Main University. Participants

The sample was simple random sampling. The calculation of sample size was done by power analysis and it included sixty critical care nursing students enrolled during the period of academic year 2014/2015. The 
critical care nursing students were randomly assigned into two equal groups: control traditional and study group, 30 per each group

Tools:

Two tools have been used in this study:

Tool I: Nursing Students' Knowledge and Practice of Acute respiratory distress syndrome Assessment Sheet

This tool was developed by the researcher based on the related literature to assess nursing students' knowledge and skills in relation to assess the baseline critical care nursing students' knowledge and nursing management regarding ARDS. It included three parts:

\section{Part (1): Socio Demographic Data}

It included data about critical care nursing students' age, marital status, qualification and previous attendance of in-service education /training regarding ARDS.

\section{Part (2): Knowledge Assessment}

This part was used to assess nursing students' knowledge in relation to ARDS in ICU. It consists of sixty questions, using two types of questions (multiple choice 42 questions and true /false 18 questions. Scoring system ranged from (0) for the incorrect answer and (1) for the correct answer. The cut point for "Good" is > $75 \%$ of the total score, "fair" is between $50 \%$ to less than $75 \%$ of the total score, and "poor" is less than $50 \%$ of the total score. It was tested for its reliability by the researcher and the value was $(0.87)$.

\section{Part (3): Students' performance checklist for nursing management of ARDS}

This part was used to assess the baseline critical care nursing students' skills regarding ARDS by using moderate fidelity simulator. It consists of four steps; patient-nurse relationship, symptom recognition, assessment, and nursing interventions of ARDS. It was divided into two columns: done (correct, incorrect) and not done. The score ranged from (0) to not done, (1) to done incorrect, and (2) to done correct performance .It was tested for its reliability by the researcher using Kappa agreement test and the value was (0.85).

\section{Tool II: "Students' Satisfaction Questionnaire":}

This tool was developed by the researcher after reviewing the related literature ${ }^{(15-7)}$.It used to determine the student satisfaction level related to the use of traditional / simulation learning strategy. It consists of 25 statements and it was included items related to structure of teaching method, learning environment, transferability, realism, and effectiveness of teaching method used. Responses ranged from strongly disagree (1) to strongly agree (4).It was tested for its reliability by the researcher using Cronbach's alpha test and the coefficient value was $(0.88)$.

\section{Data collection}

A pilot study was carried out on six students. The study has been carried out on four phases: first phase, assessment of students' knowledge and skills has been done. Second phase, preparation, ARDS teaching program (lecture and scenario case about ARDS) was developed by the researcher based on reviewing the related literature ${ }^{(9-14)}$ and the data which was obtained as a result of the assessment phase. It includes the following components:

1- General objective:-

- By the end of teaching program the critical care nursing students' knowledge and skills were improved regarding assessment and nursing intervention of ARDS.

2- Intended Learning Outcomes (ILOS):-

- By the end of teaching program the critical care nursing students' were able to:

Knowledge and understanding:

- Define ARDS in critically ill patients.

- Identify the risk factors for ARDS in ICU.

- Describe the causes of ARDS in ICU.

- Explain the Pathophysiology of ARDS in critically ill patients.

- State the different stages of ARDS in ICU.

- Discuss the nursing role toward the prevention of ARDS complications in critically ill patients.

- Recognize treatment suitable for ARDS in critically ill patient.

Intellectual capabilities:

- Compare between the different stages of ARDS in critically ill patient.

- Differentiate between the ARDS, and ALI in relation to ratio between $\mathrm{pao}_{2}$ and $\mathrm{fio}_{2}$. 
Professional and practical skills:

- Assess critically ill patients suffering from ARDS in ICU.

- Implement nursing intervention for critically ill patient suffering from ARDS.

General and transferable skills:-

- Communicate effectively with critically ill patient suffering from ARDS.

The Contents of the program:

- The theoretical contents was focus on; lecture about definitions, risk factors, hallmark features, Pathophysiology, stage, diagnosis, differentiation diagnosis, medical management, nursing care and complication of ARDS.

- The practical content was focus on scenario case about assessment and nursing intervention of ARDS in ICU.

\section{- For the theoretical content:}

\section{Implementation phase for simulation based learning group}

The program was implemented six times for the six subgroup of nursing student. All students were divided into small groups five in each. All groups were exposed to the lecture by PowerPoint presentations about ARDS. Each group of students was exposed to 4 sessions; each session toke about 30 minutes.

- Session I: included the definition, risk factors, and hallmark features of ARDS in ICU..

- Session II: included Pathophysiology, and stages of ARDS.

- Session III: included signs and symptoms, diagnosis and differentiation diagnosis of ARDS.

- Session IV: included medical management, nursing care and complication of ARDS

> In first session the researcher met the participants and explained the objectives, contents, and evaluation of the teaching program.

$>$ Group discussion was encouraged with continuous feedback to ensure understanding and achievement of intended learning outcomes.

> An open channel of communication was established between the researcher and critical care nursing students to verify any misconception and answer any question and reinforce correct actions.

> In last session the researcher summarized and emphasized the important points of ARDS in the ICU.

\section{- For practical contents:}

\section{1- Presimulation student preparation:}

Instructions to the each subgroup of students should be:

- Prior to simulation, complete assigned readings, case materials.

- Prompt to your assigned simulation time.

- Dress as in clinical.

- Wear name badge.

- Bring stethoscope.

- Address and treat mannequin as though a patient.

\section{2-Presimulation briefing}

Each subgroup of students is oriented to the mannequin and the learning environment. Then given case scenario included written clinically based patients' information related to ARDS physical examination, diagnostic test and medical management with some incomplete, uncertain or insufficient information to better reflecting the reality of clinical practice. Students are encouraged to uncover and examine and touch the mannequin, listen to the breath sounds, assess cough, palpate the pulses, and count the respiratory rate. The voice of the mannequin is demonstrated. It is important to remind students that they are to treat the mannequin as they would a patient in the scenario.

\section{3- Intrasimulation:}

Student in each subgroup were asked to assess, begin primary intervention and evaluate the effectiveness of these interventions for patient with signs and symptoms of acute respiratory distress syndrome by using human patient simulator.

\section{4-Postsimulation:}

The researcher debriefing the simulation to correct any misinformation or improper practice techniques the students may demonstrate.

Traditional learning group: nursing students in control group exposed to the traditional training through conference about ARDS 


\section{Evaluation phase}

- Reassessment of nursing students' knowledge was done using the "Acute respiratory distress syndrome Assessment Questionnaire"(tool I) immediately after finishing all sessions to determine the impact of teaching program on the students' knowledge regarding ARDS.

- Assessment of nursing students' skills was done using the "Performance checklist for assessment and nursing intervention of ARDS" (tool II) to determine the impact of simulation learning strategy on the students' skills regarding ARDS in critically ill patients.

- Assessment of students' satisfaction level related to the use of traditional / simulation learning strategy was done using "Students' Satisfaction Questionnaire"(Tool III).

- Data were collected by the researcher during approximately 3 months starting from $20{ }^{\text {th }}$ February 2015 to $20^{\text {th }}$ April 2015.

\section{Statistical analysis:}

The raw data were coded and transformed into coding sheets. The results were checked. Then, the data were entered into SPSS system files (SPSS package version 20) using personal computer. Output drafts were checked against the revised coded data for typing and spelling mistakes. Finally, analysis and interpretation of data were conducted.

- Descriptive statistics including frequency, distribution, mean, and standard deviation were used to describe different characteristics.

- Chi-square test used to compare between categorical variables where compare between continuous variables by independent and paired $\mathrm{t}$-test. Continuous variables were tested for normal distribution using KolmogoroveSmirnov test and Q-Q Plots.

- A two-tailed $\mathrm{p}<0.05$ was considered statistically significant.

\section{Ethical considerations:}

- The researcher explained to the critical care nursing students the objectives of the study orally, additionally to the written explanations on the covering letter of questionnaire.

- Critical care nursing students were assured about the confidentiality of the data collected and the right to refuse to participate in the study.

\section{Results}

The aim of this study is to determine the impact of simulation on critical care nursing students' knowledge and skills regarding the assessment and nursing intervention of acute respiratory distress syndrome. To fulfill this aim the current study results presented in the following order:

\section{Part I: studied critical care nursing students' characteristics}

Table (1): shows the distribution of the studied critical care nursing students according to their characteristics. This table indicates that all studied nursing students (100\%) aged between 20 to less than 25 years old and single. Moreover, more than two third (66.7\%) of nursing students' in control group did not attend education/training program about ARDS. While less than two third (60\%) of studied nursing students' did not attend education/training program about ARDS. The same table presents that there are no statistical significant differences between the study and control group of nursing students.

Part II: studied critical care nursing students' level of knowledge.

\section{Part II: studied critical care nursing students' level of knowledge before and after application of} traditional conference/simulation based learning about ARDS.

Table (2): demonstrates distribution of the studied critical care nursing students' level of knowledge before and after application of teaching program/traditional conference about ARDS. It was found that the majority of nursing students in both group had poor level of knowledge before application of teaching program about ARDS (96.7, 93.3 respectively). Moreover, all of the nursing students (100\%) in study group had good level of knowledge after application of teaching program about ARDS. The majority of nursing students (83.3\%) in control group had poor level of knowledge after application of traditional conference regarding ARDS.

From this table, it can be noted that there are statistical significant differences between the study and control group level of knowledge after application of traditional conference/simulation based learning about ARDS.

Table( 3) presents the mean score percentage of the studied critical care nursing students' level of knowledge before and immediately after application of teaching program / traditional conference about acute 
Impact of Using Simulation on Critical Care Nursing Students' Knowledge and Skills of Acute..

respiratory distress syndrome. It was observed that there are statistical significant differences between the nursing students' level of knowledge before and after application of teaching program in relation to definition, causes, Pathophysiology, diagnosis, nursing care, medical management and complications of ARDS in study group $(\mathrm{p}<\mathbf{0 . 0 0 1 * * )}$.

From this table, it can be noted that there are statistical significant differences between the nursing students' level of knowledge before and after application of traditional conference in relation to definition and nursing intervention of ARDS in control group $(\mathrm{p}<\mathbf{0 . 0 0 2} * \mathbf{0} \mathbf{P}<\mathbf{0 . 0 2 2 *}$ respectively). Statistical significant differences were observed between the nursing students' level of knowledge after application of teaching program / traditional conference about ARDS in both group $(\mathbf{P}<\mathbf{0 . 0 0 1 * *})$. Moreover, no statistical significant differences were observed between the nursing students' level of knowledge before application of teaching program/ traditional conference about ARDS in both group $(\mathbf{P}<0.327)$.

\section{Part III: studied critical care nursing students' level of performance for their skills after application of teaching program using simulation based learning regarding ARDS}

Table (4): illustrates distribution of the studied critical care nursing students' level of performance for their skills after application of teaching program using simulation based learning regarding ARDS. It was found that all of nursing students $(100 \%)$ in study group had good level of performance for their skills after application of simulation based learning about ARDS. Moreover, the majority of nursing students $(96.7 \%)$ in control group had poor level of performance for their skills after application of traditional conference about ARDS. From this table, it can be noted that there are statistical significant differences between the study and control group level of performance for their skills after application of traditional conference/ simulation based learning about $\operatorname{ARDS}\left(\mathrm{P}<0.001^{* * *}\right)$.

Table (5): explain the mean score percentage of the studied critical care nursing students' level of performance for their skills after application of traditional/simulation based learning regarding ARDS. It was found that the highest mean score percentage of nursing students' level of performance for their skills after application of simulation based learning in relation to endotracheal tube care $(33.3 \pm 0.9)$. While that the highest mean score percentage of nursing students' level of performance for their skills after application traditional conference in relation to tracheal suction $(21.6 \pm 3)$.

\section{Part IV: Relationships}

Table (6): describes relationship between the studied nursing students' level of knowledge regarding ARDS and their characteristics. It was observed that there are statistical significant differences between the nursing students' level of knowledge before and after application of teaching program using simulation based learning regarding ARDS in study group and their different age, marital status, qualification and attendance to training program about ARDS. From this table, it can be noted that there are statistical significant differences between the nursing students' level of knowledge in control group and the nursing students' age (less than 20 years old), marital status (single), their qualifications (secondary school) and no previous attended training courses about ARDS.

Table (7): illustrates relationship between the studied nursing students' level of performance for their skills regarding ARDS and their characteristics. It was found that there are statistical significant differences between the nursing students' level of performance after application of simulation based learning/ traditional conference regarding ARDS and their different age, marital status, qualification and attendance to training program about ARDS.

\section{Part V: studied critical care nursing students' according to their satisfaction level regarding traditional/ simulation learning strategy.}

Table(8): reveals distribution of the studied critical care nursing students' according to their satisfaction level regarding structure, transferability, and realism of traditional/ simulation learning strategy. This table shows that all of the nursing students in study group (100\%) reported that the simulation based learning helped them to clearly understood the objectives, while less than two third (60\%) of control group reported that the traditional based learning helped them to clearly understood the objectives. The majority of nursing students in study group reported that the simulation based learning provide adequate length of time with enough information in a clear matter, helpful and effective and helped them to better understand nursing concepts (93.3,93.3.96.9,93.3 respectively). While the majority of nursing students $(83.4 \%)$ in control group reported that the traditional based learning was adequate length of time.

The same table indicates that the all nursing students in study group agreed and strongly agreed that simulation learning environment was conducive, constructive and learned them from the comments made by researcher. Moreover, less than two third of the nursing students in control group agreed and strongly agreed that traditional learning environment was constructive and learned them from the comments made by researcher 
(63.4, 63.4 respectively). All of the nursing students (100\%) in study group reported that the simulation based learning experiences can be transferred to the clinical setting and helped them to improve their clinical practice. More than two third of nursing students in control group (66.7\%) agreed and strongly agreed that traditional learning helped them to improve their clinical practice.

Furthermore, the same table presents that the majority of nursing students in study group agreed and strongly agreed that simulation learning environment was recreates real-life situations, realistic and experiences can be a substitute for clinical experiences in the hospital (90\%.96.9\%,96.9\% respectively). while less than two third of nursing students $(60 \%)$ in control group agreed and strongly agreed that traditional learning experiences can be a substitute for clinical experiences in the hospital.

Statistical significant differences were observed between the nursing students study and control group related to the traditional/simulation learning helped them to clearly understand the objectives, effective, provided enough information in a clear matter, and the environment was conducive and the experiences can be transferred to the clinical setting.

Table (9): describes distribution of the studied critical care nursing students' according to their satisfaction level regarding the value of traditional/ simulation learning strategy. This table reveals that all nursing students $(100 \%)$ in study group agreed and strongly agreed that the simulation based learning helped them to less nervous in the clinical setting when providing care for similar patients, become more motivated to learn, enhanced their interaction with the researcher, enhanced their learning, was a valuable learning experience and help them to stimulate critical thinking abilities. All nursing students (100\%) in study group disagreed and strongly disagreed that the simulation based learning provokes their anxiety. The majority of nursing students in control group agreed and strongly agreed that traditional learning strategy allowed them to diagnose the learning needs and enhanced their interaction with the researcher $(80 \%, 80 \%$ respectively). Half of nursing students $(50 \%)$ in control group agreed and strongly agreed that traditional learning strategy that traditional learning strategy provokes their anxiety.

Statistical significant differences were observed between the nursing students study and control group related to that the traditional/simulation learning helped them to less nervous in the clinical setting when providing care for similar patients, become more motivated to learn, enhanced learning and thinking abilities and provokes their anxiety in the clinical setting.

\section{Discussion}

Critical care nursing students have minimal opportunities to work in a critical care setting during their clinical practicum, yet it is important that they recognize signs of deterioration in patient status and are knowledgeable about appropriate assessments and interventions. Students on the clinical unit have limited opportunities to participate in emergent situations. The patient simulator allows for purposeful exposure to critical care scenarios that the learner may not encounter in the clinical practicum. Acquisition of this type of experience is important because the nurse needs to intervene promptly to prevent adverse patient outcomes ${ }^{(6)}$.

Simulation allows students to be immersed in critical care scenarios, requiring them to be active participants identifying pertinent changes in patient status and intervening appropriately, in a timely manner, to effectively treat the changes or to limit adverse outcomes. Even if they do not intervene appropriately or quickly enough and the simulated patient dies, there is educational value to be gained through debriefing ${ }^{(8)}$. Therefore this study was carried out to determine the impact of simulation on critical care nursing students' knowledge and skills regarding the assessment and nursing intervention of acute respiratory distress syndrome.

\section{Critical nursing students' knowledge regarding ARDS:}

Acute respiratory distress syndrome (ARDS) represents a complex clinical syndrome (rather than a single disease process) and carries a high risk of mortality. The severity of the clinical course, the uncertainty of the outcome, and the reliance on the full spectrum of critical care resources for treatment means that the entire health care team is challenged. A key role for the critical care nurse is early detection and prevention of ARDS. Evidence suggests that lack of education is a major reason for poor recognition rates by nurses and other health care workers. Therefore, with respect to ARDS, it is essential for critical care nursing students to be knowledgeable of risk factors, assessment tools and protocols, and preventive strategies ${ }^{(4)}$.

Results of the current study revealed that the nursing students' level of knowledge before application of traditional conference/simulation based learning about ARDS was generally poor because of insufficient knowledge and minimal educational emphasis on ARDS in nursing schools, faculty of nursing ,absence of teaching materials, human patient simulators for undergraduate nursing education about assessment and intervention of ARDS in ICU and absence of in service education and training program regarding ARDS in critically ill patient.

Jeffries \& Rizzolo (2012) ${ }^{(18)}$ supported the current study result, they found that the use of human patient simulators for undergraduate nursing education and evaluation offers an excellent means by which to 
provide learning experiences and to measure competency of knowledge and skills. In the simulation lab, students collaborate in patient care as they conduct assessments; monitor physiologic parameters such as vital signs, heart sounds, breath sounds, and symptoms; perform nursing interventions; obtain and carry out physician's orders; administer medications; and evaluate patient responses. This type of learning activity allows the learners to synthesize and apply knowledge they have gained from structured courses and/or clinical experiences.

Human patient simulation is a relatively new teaching strategy that allows learners to develop, refine, and apply knowledge and skills in a realistic clinical situation as they participate in interactive learning experiences designed to meet their educational needs ${ }^{(17)}$.Nursing educators are challenged to teach students to think critically, to go beyond simply "knowing," to advance to synthesis and application of knowledge as they assess, plan, implement, and evaluate nursing care. Simulation provides an alternative to the traditional teachercentered approach to nursing education with emphasis on the learning needs and preferences of contemporary nursing students. The present study indicated that the level of nursing students' knowledge after application of simulation based learning about ARDS was generally good. This may be due to knowledge developed through application of the teaching program with PowerPoint presentations to the critical care nursing students which focus on; definitions, incidence, causes and risk factors, pathophysiology, diagnosis, medical management and nursing intervention about ARDS.

In this respect, Bambini, et al. (2013) $)^{(19)}$ recommended that induction of simulation based learning experiences about ARDS can be effective in increasing student's knowledge and self-efficacy in performing clinical skills. They noted that simulation may provide the bridge between theory and clinical practice by providing a safe learning environment.

The present study indicated that the level of nursing students' knowledge after application of traditional conference learning about ARDS was generally poor. This may be due to lack of consistency in students' clinical experiences. The traditional model of undergraduate clinical education dictates that students are assigned to groups of 18 , supervised by a clinical faculty, working in a health care setting for several hours at a time. Students are placed throughout hospitals and community agencies, working on a variety of units. There is inevitably lack of consistency in student learning experiences. Even students assigned to the same unit will encounter individual patients with unique problems and needs. It is impossible to assure that every student who graduates from a nursing education program will have had the same opportunity to provide care for any specific type of patient.

Results of the present study revealed that a statistical significant differences between the study and control group level of knowledge after application of traditional conference/simulation based learning about ARDS. The same result was found in the study of Jeffries \& Rizzolo (2012) ${ }^{(18)}$ found that a statistically significant differences between pre- and posttest scores for students' knowledge and showed improvement in knowledge gain after application of sumilation based learning about ARDS. In respect to Radhakrishnan et al ,(2013) ${ }^{(20)}$ recommended that the use of Human patients simulation significantly improves three outcomes integral to clinical reasoning: knowledge acquisition, critical thinking, and the ability to identify deteriorating patients.

Linier and colleagues $(2012)^{(21)}$ demonstrated the effectiveness of scenario-based simulation training on nursing students' clinical skills and competence. A sample of 99 undergraduate nursing students in the United Kingdom was divided into control and experimental groups, with the experimental group being exposed to patient simulation training using the Laerdal SimMan. Students in both groups completed a pretest and posttest as well as a questionnaire. There was a statistically significant difference in the mean scores of the two groups from pretest to post-test, with the experimental group demonstrating higher overall scores.

\section{Critical care nursing students' skills regarding ARDS:}

The use of simulation as a teaching strategy in assessment and nursing care of acute respiratory distress syndrome can contribute to patient safety and optimize outcomes of care, providing learners with opportunities to experience scenarios and intervene in clinical situations within a safe, supervised setting without posing a risk to a patient. The present study indicated that the nursing students level of performance for their skills after application of simulation based learning were generally good. This may be due to Simulation allows a condensing of vital learning experiences that assists the nursing students in developing clinical reasoning and decision making skills. Additionally, a simulation can be repeated to allow students to correct misconceptions, fill in knowledge gaps, and performe clinical skills. This can be beneficial in boosting self-confidence and selfesteem as students are learning to think and act like nurses. The nursing students actively particiated in the care of the human patient sumilation. The students' response are performed under real time and in a realistic setting as oppesed to the imagineed setting of conference or lectures.

These findings are in the line with another studies conducted by Alinier et al., (2012) ${ }^{(22)}$; Radhhakrishnan et al (2013) ${ }^{(20)}$ which suggested the effectiveness of human patient sumilation on clinical skill 
performance. Although clinical skill performance was assessed at various intervals and with different methods, the results indicate that the nursing students level of performance for their skills were generally good after application of simulation based learning and nursing students had significantly higher skills identification and vital signs assessment.The Simulated learning experiences with the patient simulator allow faculty to expose students to situations that they may never see in their clinical practicum experiences.

The present study indicated that the level of nursing students' skills after application of traditional conference learning about ARDS was generally poor. This may be due tothe students are placed in a variety of units for their clinical experiences, there is a lack of consistency in learning opportunities across and among students. Many variables influence student learning experiences in the clinical setting. These include such things as patient acuity and diagnosis, facility access, time of day, as well as clinical and teaching expertise of clinical instructors and nursing staff. Furthmore, unpredictable working environments, the need to consider patients' comfort and safety, increased attention to patients' rights and self-determination, and the shortage of field training personnel compared to the number of students. Therefore, observation-oriented practical education needs to be conducted. As a result, the satisfaction of nursing students with their clinical practice education is low and the opportunity of obtaining sufficient clinical competency through practical education is limited

Results of the present study revealed that a statistical significant differences between the study and control group level of performance for their skills after application of traditional conference/simulation based learning about ARDS. The findings of the current study were in line with; Hoffmann et al.( 2015) ${ }^{(23)}$; Howard, $(2012)^{(24)}$ Jeffries \& Rizzolo $(2006)^{(18)}$, they reported that a statstically significant improvement in the level performance post sumulation compared with traditional lecture. This in line with Benner et al $(2011)^{(25)}$ reported that the students who recieved human patient sumilation instructional methods achieved significantly higher level in performance than did those who received the traditional lecture.

\section{Relationship between nursing students' knowledge and skills regarding ARDS and their characteristics}

Few papers have addressed the predictive relationship between the demographic variables such as; age, qualifications, marital status, and attendance to training program about ARDS and nursing students' level of knowledge and skills. The result of the current study revealed that statistical significant differences between the nursing students' level of knowledge and skills regarding ARDS in study group and their different age, marital status, qualification and attendance to training program about ARDS. This may be attributed to the highest level of qualification had an association with knowledge attainment and the fact that previous training about ARDS plays important role for acquiring knowledge and clinical practice. In contrast to the finding of the current study, Aliner et al (2012) ${ }^{(22)}$ found no significant difference in the level of nursing students' knowledge and skills regarding ARDS after application of simulation based learning/traditional case study and their different age, marital status, qualification and attendance to training program about ARDS .

\section{Student satisfaction level related to the use of traditional / simulation learning strategy:}

Clinical simulations in nursing education are used to provide opportunities to practice patient care skills in a nonthreatening and safe environment. Nurse educators have used patient care simulations to enhance learners' experiences believing that when a previously simulated experience is encountered in real life, the student will be able to understand and successfully manage the situation. Simulations should help students learn necessary cognitive and psychomotor skills and allow them to develop confidence or the self-efficacy needed to perform appropriate and correct nursing actions when similar real patient situations are encountered. Until now, nursing service has used the HPS mostly in the critical care area to teach critical care nurse how to care for the critically ill patient and to test advanced cardiac life support skills. Most recently, HPS is being used in nursing programs with graduate and undergraduate students. In every aspect of patient care, hands-on experience is the best teacher.

Regarding the structure of simulation/traditional based learning the nursing students in the current study reported that the simulation based learning helped them to clearly understood the objectives, provided adequate length of time with enough information in a clear matter, effective and helped them to better understand nursing concepts. While two third of nursing students in control group in the current study reported that traditional based learning helped theme to clearly understand the objectives and adequate length of time.

This finding is in line with the studies of Calaluce, and Kallen $(2013)^{(26)}$ which revealed that the majority of students and faculty felt the simulations were realistic and valuable, only half of the students agreed that skills learned in the simulation were transferable to a real patient care setting. Faculty indicated that simulations reinforced clinical objectives and adequately tested clinical and decision making skills. Concerns of faculty members relative to patient simulator use included extra preparation time and lack of faculty support to use the technology. 
Regarding the learning environment of simulation/traditional based learning the nursing students in the current study reported that the simulation based learning environment was conducive, constructive and learned them from the comments made by the researcher. Moreover, less than two third of control group in the current study reported that traditional based learning environment was conducive and constructive.

Beaubien and Baker(2014) ${ }^{(27)}$ supported the current study result; they found that the use of the human patient simulation as a teaching tool in nursing education can provide a more interactive learning environment for students. Not only can students see a variety of complex case scenarios, they can also practice in a real lifelike situation. The student is able to work in a more controlled environment and is thus able to focus on making clinical judgments regarding clients' problem situations without fear of harm to clients. This entire process provides an environment conducive for focusing on critical thinking, clinical reasoning, and clinical judgment skills as well as acquiring knowledge.

Regarding the transferability of simulation/traditional based learning the nursing students in the current study reported that the simulation based learning experiences can be transferred to the clinical setting and helped them to improve their clinical practice. While two third of nursing students in control group reported that the traditional based learning helped them to improve their clinical practice. In this respect, Medley \& Horne, $(2015)^{(28)}$ recommended that the Simulation is an innovative and technologically advanced teaching and learning approach that combines a problem-based approach with experiential learning. The student learns through 'doing' and 'experiencing', utilizing their knowledge base, psychomotor skills and clinical decision making based.

Regarding the realism of simulation/traditional based learning the nursing students in the current study reported that the simulation based learning environment was recreates real-life situations, realistic and experiences can be a substitute for clinical experiences in the hospital. While less than two third of nursing students in control group in the current study reported that traditional based learning experiences can be a substitute for clinical experiences in the hospital. Nevin et al $(2014)^{(29)}$ supported the current study result, they found that the simulation sessions to be realistic and the majority of participants reported the simulation was useful in developing clinical skills, knowledge, confidence for clinical practice and can be a substitute for clinical experiences in the hospital.

Regarding the value of simulation/traditional based learning. The all nursing student in study group agreed and strongly agreed that the simulation based learning helped them to less nervous in the clinical setting when providing care for similar patients, become more motivated to learn, enhanced their interaction with the researcher, enhanced their learning, was a valuable learning experience and help them to stimulate critical thinking abilities.

The result of the current study is supported by Butlas et al $(2013)^{(30)}$ that asserted the use of human patient simulation providing a foundation for supporting an effective teaching modality. Students reported that the simulation experience helped them recognize their knowledge gap and prepared them understanding the scenario content. Furthermore participants reported that the simulation experience provided them the opportunity to problem solve and critically think the situations during the simulation sessions.

This finding concurs with Kaddoura's $(2014)^{(31)}$ study in that the report indicate simulation has helped new graduates learn to improve their critical thinking and confidence, and made sound clinical decisions to improve patient outcomes. Students were comfortable with their knowledge of the clinical content covered during the simulation scenario and able to reflect on their own simulation experience. The result of the current study is supported by Clark et al (2012) ${ }^{(32)}$ who finding that students in the simulation group had higher scores when asked if the experiences were a valuable learning experience as compared to the traditional learning group. Therefore, the students in the simulation group perceived the learning experience to be more valuable than those in the traditional learning group The result of the current study revealed that all nursing students in study group disagreed and strongly disagreed that the simulation based learning provokes their anxiety. In contrast the findings of the current study conducted by Kim H, Lee A et al (2015) ${ }^{(33)}$ which suggested that the simulation helped nursing students learn how to address the patient effective communication, reducing anxiety, and prioritizing the patients' needs. But, along with the attraction to the technology, there is also the negative aspect of anxiety provoked by the simulation and the expectation for the student to competently complete the exercise.

The current study demonstrated that Statistical significant differences were observed between the nursing satisfaction level in the study and control group related to the use of traditional / simulation learning strategy. The findings of the current study were in line with Howard, $(2012)^{(24)}$ how found that the significant differences in the level of satisfaction with simulation activities among undergraduate students compared with the case study approach. 
Current evidences show that students are expected to obtain knowledge and skills necessary for providing safe and effective patient care in the clinical setting ${ }^{(34,35)}$. Clinical, hands-on practice is crucial for the education of healthcare professionals. Inexperienced students increase the risk of errors, thus putting patients in danger; however students must have the opportunity to practice clinical skills and procedures before working independently with patients. These ethical considerations limit the opportunities students have for practice in the clinical setting. Simulation offers a method to practice skills in a safe environment prior to working with patients in an actual clinical setting. Practicing in this type of simulated, "safe" setting allows students to make mistakes without fear of harming real patients.

Tables: Table (1): Distribution of the studied critical care nursing students according to their characteristics

\begin{tabular}{|c|c|c|c|c|c|}
\hline \multirow{2}{*}{$\begin{array}{l}\text { Nursing students' } \\
\text { characteristics }\end{array}$} & \multicolumn{2}{|c|}{ Study } & \multicolumn{2}{|c|}{ Control } & \multirow{2}{*}{ P. value } \\
\hline & No. & $\%$ & No. & $\%$ & \\
\hline \multicolumn{6}{|l|}{ Demographic data } \\
\hline \multicolumn{6}{|l|}{ Age } \\
\hline $20:<25$ year & 30 & $\underline{100}$ & 30 & $\underline{100}$ & 0.033 \\
\hline \multicolumn{6}{|l|}{ Marital status } \\
\hline Single & 30 & $\underline{100.0}$ & 26 & $\underline{86.7}$ & \multirow[t]{2}{*}{0.038} \\
\hline Married & 0 & 0.0 & 4 & 13.3 & \\
\hline \multicolumn{6}{|l|}{ Qualification } \\
\hline Secondary School & 27 & 90.0 & 30 & 100.0 & \multirow[t]{2}{*}{0.368} \\
\hline technical diploma & 3 & 10.0 & 0 & 0.0 & \\
\hline \multicolumn{6}{|c|}{ Attendance of in-service education/ training courses about ARDS } \\
\hline Yes & 12 & 40.0 & 10 & 33.3 & \multirow[t]{2}{*}{0.592} \\
\hline No & 18 & 60.0 & 20 & 66.7 & \\
\hline
\end{tabular}

Table (2): Distribution of the studied critical care nursing students' level of knowledge before and after application of teaching program about ARDS

\begin{tabular}{|c|c|c|c|c|c|c|c|c|c|c|}
\hline \multirow{3}{*}{$\begin{array}{l}\text { Students' } \\
\text { Knowledge } \\
\text { regarding ARDS }\end{array}$} & \multicolumn{4}{|c|}{ Study } & \multicolumn{4}{|c|}{ Control } & \multirow[t]{3}{*}{ P1 } & \multirow[t]{3}{*}{$\mathbf{P 2}$} \\
\hline & \multicolumn{2}{|l|}{ Pre } & \multicolumn{2}{|c|}{ Post } & \multicolumn{2}{|l|}{ Pre } & \multicolumn{2}{|c|}{ Post } & & \\
\hline & No. & $\%$ & No. & $\%$ & No. & $\%$ & No. & $\%$ & & \\
\hline Poor & 29 & 96.7 & 0 & 0.0 & 28 & 93.3 & 25 & 83.3 & \multirow[t]{3}{*}{0.554} & \multirow[t]{3}{*}{$<0.001 * *$} \\
\hline Fair & 1 & 3.3 & 0 & 0.0 & 2 & 6.7 & 5 & 16.7 & & \\
\hline Good & 0 & 0.0 & 30 & 100.0 & 0 & 0.0 & 0 & 0.0 & & \\
\hline P. value & \multicolumn{4}{|c|}{$<0.001 * *$} & \multicolumn{4}{|c|}{0.224} & & \\
\hline
\end{tabular}

P1: Comparison between study and control in pre test

P2: Comparison between study and control in post test

* Significant difference $(\mathrm{p}<0.05)$

$* *$ Significant difference $(\mathrm{p}<0.01)$

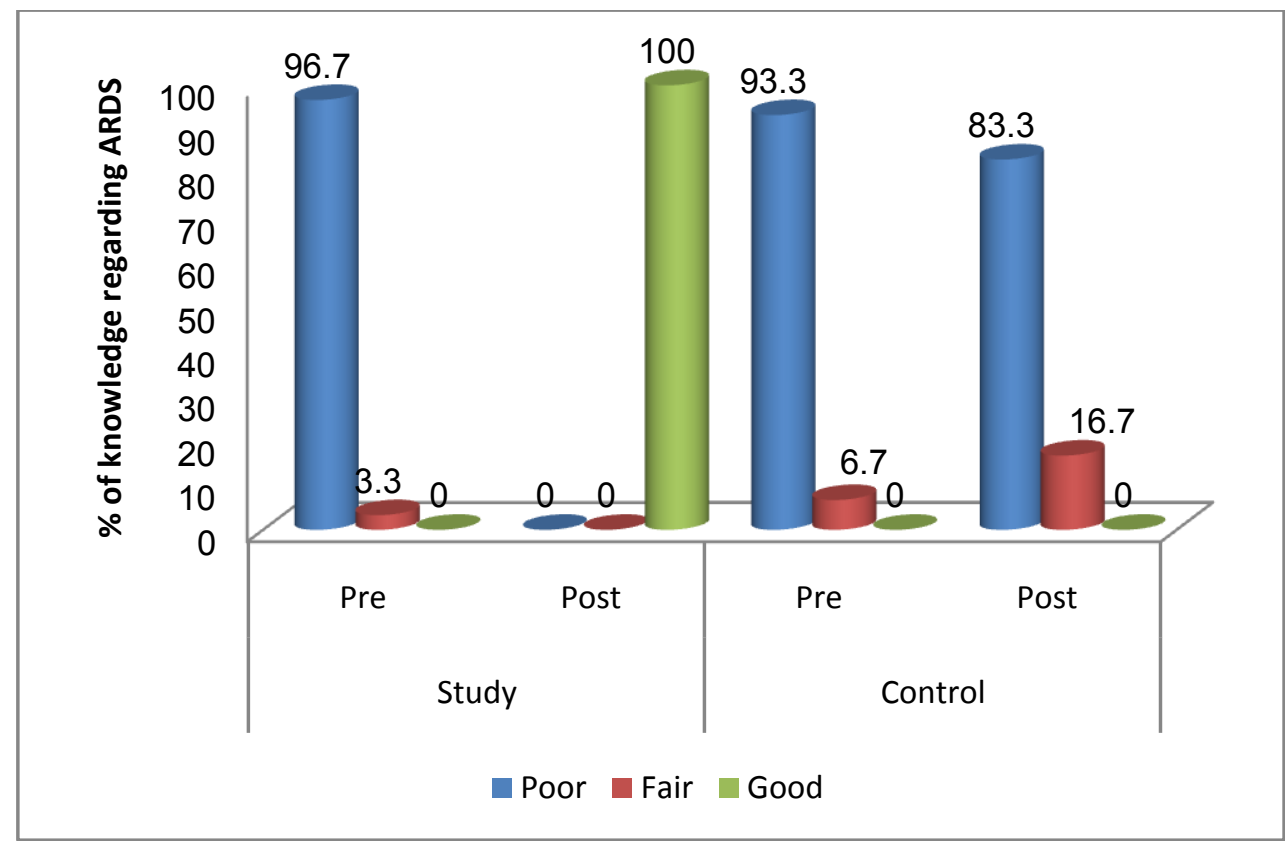

Figure (1): Distribution of the studied critical care nursing students' level of knowledge before and after application of teaching program about ARDS 
Impact of Using Simulation on Critical Care Nursing Students' Knowledge and Skills of Acute..

Table( 3) the mean score percentage of the studied critical care nursing students' level of knowledge before and immediately after application of teaching program about acute respiratory distress syndrome

\begin{tabular}{|c|c|c|c|c|c|c|c|c|}
\hline \multirow{2}{*}{$\begin{array}{l}\text { Nursing students' } \\
\text { knowledge } \\
\text { regarding ARDS }\end{array}$} & \multicolumn{2}{|l|}{ Study } & \multirow[t]{2}{*}{ P. value } & \multicolumn{2}{|l|}{ Control } & \multirow{2}{*}{ P. value } & \multirow[t]{2}{*}{ P1 } & \multirow[t]{2}{*}{$\mathbf{P 2}$} \\
\hline & Pre & Post & & Pre & Post & & & \\
\hline Definition & $1.9 \pm 1.2$ & $5.7 \pm 0.6$ & $<0.001 * *$ & $1.7 \pm 0.9$ & $2.6 \pm 1.2$ & $0.002 * *$ & 0.464 & $<0.001 * *$ \\
\hline Risk factors \&Causes & $2.1 \pm 1$ & $3.9 \pm 0.3$ & $<0.001 * *$ & $2 \pm 0.8$ & $2.5 \pm 1.1$ & 0.076 & 0.777 & $<0.001 * *$ \\
\hline Pathophysiology & $5.2 \pm 1.6$ & $12.5 \pm 0.8$ & $<0.001 * *$ & $5.1 \pm 2.3$ & $5.7 \pm 2$ & 0.264 & 0.799 & $<0.001 * *$ \\
\hline Signs \& symptoms & $4.5 \pm 2.1$ & $12.7 \pm 0.5$ & $<0.001 * *$ & $4.3 \pm 2.1$ & $4.7 \pm 2.2$ & 0.479 & 0.711 & $<0.001 * *$ \\
\hline Diagnosis & $3.1 \pm 1.1$ & $6.8 \pm 0.4$ & $<0.001 * *$ & $2.7 \pm 1$ & $2.9 \pm 1.2$ & 0.421 & 0.120 & $<0.001 * *$ \\
\hline Nursing intervention & $0.9 \pm 0.7$ & $4 \pm 0$ & $<0.001 * *$ & $1 \pm 0.8$ & $1.5 \pm 0.8$ & $0.022 *$ & 0.618 & $<0.001 * *$ \\
\hline Medical management & $3.1 \pm 1.9$ & $9.8 \pm 0.5$ & $<0.001 * *$ & $3.1 \pm 1.5$ & $3.4 \pm 1.5$ & 0.497 & 1.000 & $<0.001 * *$ \\
\hline Complications & $1.2 \pm 0.7$ & $3 \pm 0$ & $<0.001 * *$ & $1.1 \pm 0.8$ & $1.3 \pm 0.7$ & 0.314 & 0.494 & $<0.001 * *$ \\
\hline Total & $22 \pm 4$ & $58.3 \pm 1.5$ & $<0.001 * *$ & $21 \pm 4.3$ & $24.6 \pm 6.9$ & 0.018* & 0.327 & $<0.001 * *$ \\
\hline
\end{tabular}

P1: Comparison between study and control in pre test

P2: Comparison between study and control in post test

* Significant difference $(\mathrm{p}<0.05)$

** Significant difference $(\mathrm{p}<0.01)$

Table (4): Distribution of the studied critical care nursing students' level of performance for their skills after application of traditional /simulation based learning regarding ARDS

\begin{tabular}{|l|l|l|l|l|l|}
\hline \multirow{2}{*}{ Level of Performance } & Study & Control & \multirow{2}{*}{ P. value } \\
\cline { 2 - 5 } & No. & \% & No. & \% & \\
\hline Poor & 0 & 0 & 29 & 96.7 & \multirow{2}{*}{$<0.001 * *$} \\
\hline Fair & 0 & 0 & 1 & 3 & \\
\hline Good & 30 & $\underline{100}$ & 0 & 0 & \\
\hline
\end{tabular}

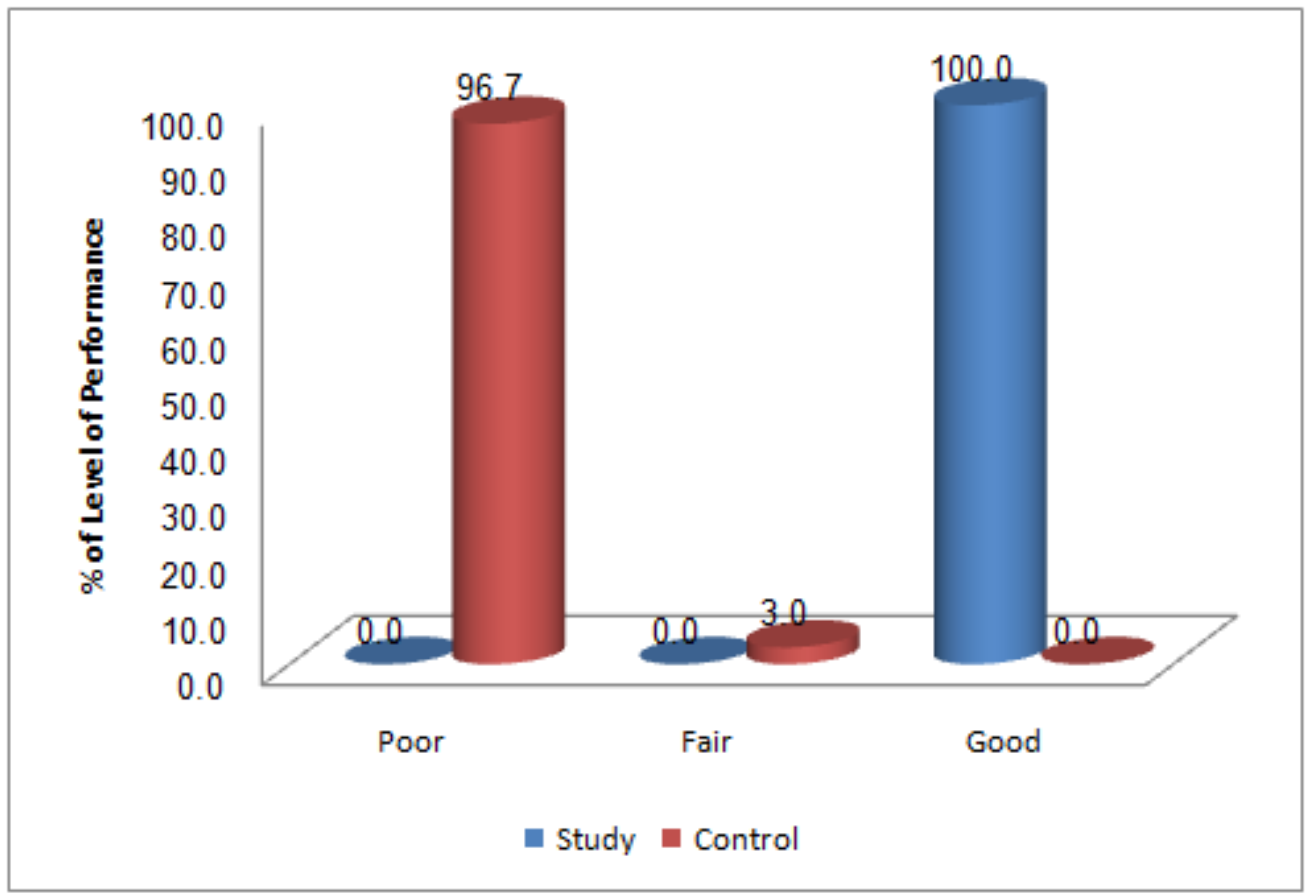

Figure (2): Distribution of the studied critical care nursing students' level of performance for their skills after application of traditional /simulation based learning regarding ARDS

Table (5) the mean score percentage of the studied critical care nursing students' level of performance for their skills after application of traditional /simulation based learning regarding ARDS

\begin{tabular}{|ll|l|l|l|}
\hline Performance checklist & Study & Control & P. value \\
\hline$\bullet$ & Patient nurse relationship & $4.7 \pm 1.5$ & $0.9 \pm 1$ & $<0.001^{* *}$ \\
\hline$\bullet$ & Symptom recognition & $17.8 \pm 0.8$ & $9.5 \pm 1.5$ & $<0.001^{* *}$ \\
\hline$\bullet$ & Assessment & $21.7 \pm 0.6$ & $7.8 \pm 1.8$ & $<0.001^{* *}$ \\
\hline$\bullet$ & Nursing interventions & $8 \pm 0$ & $3.8 \pm 0.9$ & $<0.001^{* *}$ \\
\hline$\bullet$ & Tracheal suction as patient needed & $47 \pm 1.1$ & $21.6 \pm 3$ & $<0.001^{* *}$ \\
\hline$\bullet$ & Endotracheal tube care & $33.3 \pm 0.9$ & $14.5 \pm 3$ & $<0.001^{* *}$ \\
\hline$\bullet$ & Decreased body temperature & $7.8 \pm 0.5$ & $0.3 \pm 0.7$ & $<0.001^{* *}$ \\
\hline Total mean score & $140.2 \pm 1.9$ & $58.4 \pm 5$ & $<0.001^{* *}$ \\
\hline
\end{tabular}


Impact of Using Simulation on Critical Care Nursing Students' Knowledge and Skills of Acute..

Table (6): Relationship between the studied nursing students' level of knowledge regarding ARDS and their characteristics.

\begin{tabular}{|c|c|c|c|c|c|c|}
\hline \multirow[t]{3}{*}{ Nursing students' characteristics } & \multicolumn{6}{|c|}{ Nursing students' level of knowledge } \\
\hline & \multicolumn{2}{|c|}{ Simulation group } & \multirow[t]{2}{*}{ P. value } & \multicolumn{2}{|c|}{ Traditional conference group } & \multirow[t]{2}{*}{ P. value } \\
\hline & Pretest & Post-test & & Pretest & Post-test & \\
\hline \multicolumn{7}{|l|}{ Age } \\
\hline$<20$ year & $22.8 \pm 4.6$ & $58.7 \pm 0.8$ & $<0.001 * *$ & $19 \pm 3.2$ & $25.9 \pm 7.9$ & $0.010^{*}$ \\
\hline $20:<25$ year & $21.7 \pm 3.8$ & $58.1 \pm 1.7$ & $<0.001 * *$ & $22.3 \pm 4.6$ & $23.7 \pm 6.1$ & 0.442 \\
\hline \multicolumn{7}{|l|}{ Marital status } \\
\hline Single & $22+4$ & $58.3 \pm 1.5$ & $<0.001 * *$ & $20.8+4.5$ & $24.2 \pm 7$ & $0.042 *$ \\
\hline Married & - & - & - & $22.3 \pm 3.1$ & $27 \pm 5.6$ & 0.192 \\
\hline \multicolumn{7}{|l|}{ Qualification } \\
\hline Secondary School & $22+4.1$ & $58.3 \pm 1.5$ & $<0.001 * *$ & $21 \pm 4.3$ & $24.6 \pm 6.9$ & $0.018^{*}$ \\
\hline technical diploma & $18 \pm 0$ & $58 \pm 0$ & $<0.001 * *$ & - & - & \\
\hline \multicolumn{7}{|c|}{ Attendance of training courses about ARDS } \\
\hline Yes & $23.2 \pm 4$ & $58.4 \pm 1.2$ & $<0.001 * *$ & $22+5.2$ & $25.7 \pm 7.6$ & 0.221 \\
\hline No & $21.3 \pm 4$ & $58.2 \pm 1.7$ & $<0.001^{* *}$ & $20.5 \pm 3.9$ & $24 \pm 6.6$ & $0.048^{*}$ \\
\hline
\end{tabular}

Table (7): Relationship between the studied nursing students' level of performance for their skills regarding ARDS and their characteristics

\begin{tabular}{|c|c|c|c|}
\hline \multirow[t]{2}{*}{ Nursing students' characteristics } & \multicolumn{2}{|c|}{ Nursing students' skills } & \multirow[t]{2}{*}{ P. value } \\
\hline & Simulation group & Traditional conference group & \\
\hline \multicolumn{4}{|l|}{ Age } \\
\hline$<20$ year & $140.1 \pm 1.9$ & $58.8+4.5$ & $<0.001 * *$ \\
\hline $20:<25$ year & $140.3+1.9$ & $58.1+5.4$ & $<0.001 * *$ \\
\hline \multicolumn{4}{|l|}{ Marital status } \\
\hline Single & $140.2+1.9$ & $57.8+4.4$ & $<0.001^{* *}$ \\
\hline Married & - & $62 \pm 7.6$ & - \\
\hline \multicolumn{4}{|l|}{ Qualification } \\
\hline Secondary School & $140.3 \pm 1.9$ & $58.4+5$ & $<0.001 * *$ \\
\hline Technical diploma & $142+0$ & - & - \\
\hline \multicolumn{4}{|c|}{ Attendance of training courses about ARDS } \\
\hline Yes & $140.3 \pm 2$ & $58.1+3.7$ & $<0.001^{* *}$ \\
\hline No & $140.2+1.8$ & $58.5+5.6$ & $<0.001^{* *}$ \\
\hline
\end{tabular}

Table(8): Distribution of the studied critical care nursing students' according to their satisfaction level regarding the structure and learning environment of traditional/ simulation learning strategy

\begin{tabular}{|c|c|c|c|c|c|c|c|c|c|}
\hline \multirow[t]{3}{*}{ Student satisfaction } & \multicolumn{4}{|c|}{ Control } & \multicolumn{4}{|c|}{ Study } & \multirow[t]{3}{*}{$P$ value } \\
\hline & \multicolumn{2}{|c|}{$\begin{array}{ll}\text { Agree } & \& \\
\text { strongly } & \\
\text { agree } & \\
\end{array}$} & \multicolumn{2}{|c|}{$\begin{array}{l}\text { Disagree \& } \\
\text { strongly } \\
\text { disagree } \\
\end{array}$} & \multicolumn{2}{|c|}{$\begin{array}{l}\text { Agree } \quad \& \\
\text { strongly agree }\end{array}$} & \multicolumn{2}{|c|}{$\begin{array}{l}\text { Disagree \& } \\
\text { strongly } \\
\text { disagree }\end{array}$} & \\
\hline & No & $\%$ & No & $\%$ & No & $\%$ & No & $\%$ & \\
\hline \multicolumn{10}{|l|}{$\begin{array}{l}\text { Structure } \\
\text { The traditional/simulation learning }\end{array}$} \\
\hline $\begin{array}{l}\text { - Helped me to clearly understood the } \\
\text { objectives }\end{array}$ & 18 & $\underline{60 \%}$ & 12 & $40 \%$ & 30 & $\underline{100}$ & 0 & 0 & $<0.001 * *$ \\
\hline - Adequate length of time & 25 & $\underline{83.4}$ & 5 & 16.6 & 28 & $\underline{93.3}$ & 2 & 6.7 & .059 \\
\hline - helpful and effective & 20 & 66.7 & 10 & 30.3 & 29 & 96.9 & 1 & 3.33 & $<0.001 * *$ \\
\hline $\begin{array}{l}\text { - provided me with enough information in a } \\
\text { clear matter }\end{array}$ & 16 & 53.3 & 14 & 46.4 & 28 & $\underline{93.3}$ & 2 & 6.7 & $<0.001 * *$ \\
\hline $\begin{array}{l}\text { - helped me to better understand nursing } \\
\text { concepts }\end{array}$ & 16 & 53.3 & 14 & 46.7 & 28 & $\underline{93.3}$ & 2 & 6.7 & .001 \\
\hline \multicolumn{10}{|l|}{ Learning environment } \\
\hline $\begin{array}{l}\text { - environment was conducive ( (محفزة to my } \\
\text { learning }\end{array}$ & 17 & 56.6 & 13 & 43.3 & 30 & $\underline{100}$ & 0 & 0 & $<0.001 * *$ \\
\hline - Feedback provided was constructive (بناء) & 19 & $\underline{63.4}$ & 11 & 36.7 & 30 & $\underline{100}$ & 0 & 0 & .003 \\
\hline $\begin{array}{l}\text { - Assessed me learned from the comments } \\
\text { made by my researcher }\end{array}$ & 19 & $\underline{63.4}$ & 11 & 36.7 & 30 & $\underline{100}$ & 0 & 0 & .003 \\
\hline \multicolumn{10}{|l|}{$\begin{array}{l}\text { Transferability } \\
\text { The traditional/simulation based learning: }\end{array}$} \\
\hline $\begin{array}{l}\text { - Experiences can be transferred (تتنقل) to the } \\
\text { clinical setting }\end{array}$ & 16 & 53.3 & 14 & 46.4 & 30 & $\underline{100}$ & 0 & 0 & $<0.001 * *$ \\
\hline - helped me to improve my clinical practice & 20 & $\underline{66.7}$ & 10 & 30.3 & 30 & $\underline{100}$ & 0 & 0 & .002 \\
\hline - prepared me to practice clinical setting & 17 & 56.6 & 13 & 43.3 & 28 & 93.3 & 2 & 6.7 & .001 \\
\hline \multicolumn{10}{|l|}{$\begin{array}{l}\text { Realism } \\
\text { The traditional/simulation based learning: }\end{array}$} \\
\hline recreates real-life situations & 17 & 56.6 & 13 & 43.3 & 27 & $\underline{90}$ & 3 & 10 & .002 \\
\hline were realistic & 16 & 53.3 & 14 & 46.4 & 29 & 96.9 & 1 & 3.33 & .001 \\
\hline
\end{tabular}


Impact of Using Simulation on Critical Care Nursing Students' Knowledge and Skills of Acute..

\begin{tabular}{|l|l|l|l|l|l|l|l|l|l|l|}
\hline $\begin{array}{l}\text { experiences can be a substitute for clinical } \\
\text { experiences in the hospital }\end{array}$ & 18 & $\underline{60}$ & 12 & 40 & 29 & $\underline{96.9}$ & 1 & 3.33 & $\mathbf{. 0 0 2}$ \\
\hline
\end{tabular}

Table (9): Distribution of the studied critical care nursing students' according to their satisfaction level regarding the value of traditional/ simulation learning strategy

\begin{tabular}{|c|c|c|c|c|c|c|c|c|c|}
\hline \multirow[t]{3}{*}{ Student satisfaction } & \multicolumn{4}{|c|}{ Control } & \multicolumn{4}{|c|}{ Study } & \multirow[t]{3}{*}{ P value } \\
\hline & \multicolumn{2}{|c|}{$\begin{array}{l}\text { Agree } \& \\
\text { strongly agree }\end{array}$} & \multicolumn{2}{|c|}{$\begin{array}{ll}\text { Disagree } \& \\
\text { strongly } \\
\text { disagree }\end{array}$} & \multicolumn{2}{|c|}{$\begin{array}{l}\text { Agree } \quad \& \\
\text { strongly agree }\end{array}$} & \multicolumn{2}{|c|}{$\begin{array}{ll}\text { Disagree } \quad \& \\
\text { strongly } \\
\text { disagree }\end{array}$} & \\
\hline & No & $\%$ & No & $\%$ & No & $\%$ & No & $\%$ & \\
\hline \multicolumn{10}{|l|}{$\begin{array}{l}\text { Value } \\
\text { The traditional / simulation based learning }\end{array}$} \\
\hline - helped me to meet my learning objectives & 19 & 53 & 11 & 36.7 & 27 & 90 & 3 & 10 & .003 \\
\hline $\begin{array}{l}\text { - allowed me to diagnose my own learning } \\
\text { needs }\end{array}$ & 18 & $\underline{80}$ & 12 & 39.7 & 28 & 93.3 & 2 & 6.9 & .009 \\
\hline $\begin{array}{l}\text { - Helped me to less nervous in the clinical } \\
\text { setting when providing care for similar } \\
\text { patients }\end{array}$ & 15 & 50 & 15 & 50 & 30 & $\underline{100}$ & 0 & 0 & $<0.001 * *$ \\
\hline - helped me to become more motivated to learn & 19 & 63.3 & 11 & 33.6 & 30 & $\underline{100}$ & 0 & 0 & $<0.001 * *$ \\
\hline $\begin{array}{l}\text { - promotes the interaction between me and my } \\
\text { researcher }\end{array}$ & 24 & $\underline{80}$ & 6 & 20 & 30 & $\underline{100}$ & 0 & 0 & .017 \\
\hline $\begin{array}{l}\text { - promotes the interaction between me and my } \\
\text { colleagues }\end{array}$ & 16 & 53.3 & 14 & 46.4 & 28 & 93.3 & 2 & 6.9 & .001 \\
\hline - experience enhanced my learning & 17 & 56.6 & 13 & 43.3 & 30 & $\underline{100}$ & 0 & 0 & $<0.001 * *$ \\
\hline - was a valuable learning experience. & 16 & 53.3 & 14 & 46.4 & 30 & $\underline{100}$ & 0 & 0 & $<0.001 * *$ \\
\hline - helped to stimulate critical thinking abilities & 15 & 50 & 15 & 50 & 30 & 100 & 0 & 0 & $<0.001 * *$ \\
\hline - Provokes anxiety in the clinical setting & 15 & 50 & 15 & 50 & 0 & 0 & 30 & $\begin{array}{l}10 \\
0\end{array}$ & $<0.001 * *$ \\
\hline
\end{tabular}

\section{Conclusion and recommendation}

The present study highlights the critical care nursing knowledge and skills regarding ARDS Based on the results of this study, it can be concluded that:

- All of the nursing students in study group had good level of knowledge and skills after application of simulation based learning about ARDS.

- The majority of nursing students in control group had poor level of knowledge and skills after application of traditional conference regarding ARDS.

- A statistical significant differences between the study and control group level of knowledge and skills after application of traditional conference/simulation based learning about ARDS.

\section{Recommendations:}

Based on the findings of the current study, the following recommendations can be suggested:

- Consider open lab time for students in faculty of nursing to be able to interact with the mannequins using various scenarios, staffed by qualified instructors.

- Consider further studies about exploring the effect of simulation based learning on the nursing students' critical thinking and problem solving skills.

- Prevention, assessment and early detection of ARDS in critically ill patients should be integrated in the undergraduate courses to equip the students with the necessary knowledge and skills that enable them for identifications of ARDS in the ICUs.

- Integrating simulation-based learning in the undergraduates courses with the traditional teaching strategies.

\section{References}

[1]. Morton P, Fontaine D, Hudak C, Gallo B. Critical care nursing: A holistic approach.6thed. Philadelphia .Lippincott - Williams \& Wilkins. 2013: 40-1.

[2]. Wheeler AP, Bernard GR. Acute Lung Injury and the Acute Respiratory Distress Syndrome: A Clinical Review. Lancet.(2010); (369):1553-64.

[3]. National Institutes of Health. National Heart, Lung and Blood Institute.Diseases and Conditions Index. Acute Respiratory Distress Syndrome (ARDS): What Is ARDS? (2011).Available@http://www.nhlbi.nih.gov/health/dci/Diseases/Ards/Ards_WhatIs.html. Accessed on 5/6/2015.

[4]. Koh Y. Update in acute respiratory distress syndrome. Journal of Intensive Care (2014); 2(2):1-6.

[5]. Lee, J. H., \& Choi, M. Evaluation of effects of a clinical reasoning course among undergraduate nursing students. Korean Journal of Adult Nursing. (2011); 23 (1):1-9.

[6]. Ravert P. Use of a human patient simulator with undergraduate nursing students: a prototype evaluation of critical thinking and selfefficacy. Journal of the American Association of Nurse Anesthetists (2014);63(1): 61-7.

[7]. Rhodes M, Curran C.Use of the human patient simulator to teach clinicaljudgment skills in a baccalaureate nursing program. Computers, Informatics, Nursing (2013); 23 (5): 256-62. 
[8]. Dearman C, Lazenby R, Faulk D, Coker R. Simulated clinical scenarios: faculty-student collaboration. Nursing Educationtoday.(2011);26:167-9.

[9]. Ashbaugh D, Bigelow D, Petty T, Levine B: Acute respiratory distress in adults. Lancet.(2013); 2:319-23.

[10]. Bakowitz A, MagdalenaL ."Acute lung injury and the acute respiratory distress syndrome in the injured patient".Scandinavian Journal of Trauma, Resuscitation and Emergency Medicine.(2012);111(3):5-9

[11]. Bernard G, Artigas A, Brigham K, Carlet J, Falke K, Hudson L, Lamy M, Legall J, Morris A, Spragg R . "The American-European Consensus Conference on ARDS.Definitions, mechanisms, relevant outcomes, and clinical trial coordination".Am J RespirCrit Care $\operatorname{Med}(2010) ; 149 .(3): 818-24$.

[12]. Grasso S, Stripoli T, De Michele M ."ARDS net ventilatory protocol and alveolar hyperinflation: role of positive end-expiratory pressure". Am. J. Respir. Crit. Care Med (2010);176 (8): 761-7.

[13]. Vlaar A, Binnekade J, PrinsD . "Risk factors and outcome of transfusion-related acute lung injury in the critically ill: a nested casecontrol study". Crit Care Med(2010);38 (3): 771-8.

[14]. Sud S, Friedrich JO, AdhikariN.."Effect of prone positioning during mechanical ventilation on mortality among patients with acute respiratory distress syndrome: a systematic review and meta-analysis". CMAJ (2014); 186 (10): E381-90.

[15]. Bremner, M. N., Aduddell, K., Bennett, D. N., \&VanGeest, J. B. The use of human patient simulators: Best practices with novice nursing students. Nurse Educator (2015); 31(4): 170-4.

[16]. Goldenberg, D., Andrusyszyn, M., Iwasiw, C. The effect of classroom simulation on nursing students' self-efficacy related to health teaching. Journal of Nursing Education,(2015); 44(7): 310-4.

[17]. Ravert P.Use of a human patient simulator with undergraduate nursing students: A prototype evaluation of critical thinking and self-efficacy. Unpublished Ph.D.University of Utah(2014).

[18]. Jeffries, P,Rizzola, M. Designing and implementing models for the innovative use of simulation in teaching nursing care of ill adults and children: A national, multi-site, multi-method study.(2012) New York, NY: National League for Nursing. retrieved from www.nln.org/research/LaerdalReport.pdf.

[19]. Bambini D., Washburn, J, \& Perkins, R. Outcomes of clinical simulation for novice nursing students: Communication, confidence, clinical judgment. Nursing Education Perspectives, (2013);30(2):79-82.

[20]. Radhakrishnan, K., Roche, J., Cunningham, H. Measuring clinical practice parameters with human patient simulation: A pilot study. International Journal of Nursing Scholarship, (2013); 4(1):1-11.

[21]. Linier and colleagues.Simulation-enhanced pediatric clinical orientation. Journal of Nursing Education(2012); 50(8):461-5.

[22]. Alinier G., Hunt B., Gordon R.\& Harwood C. Effectiveness of intermediate-fidelity simulation training technology in undergraduate nursing education. Journal of Advanced Nursing (2012);54(3): 359-69.

[23]. Hoffmann, R.M., Stevenson, M., Downie, W.W., Wilson, G.M. Assessment of clinical competence using objective structure examination. British Medical Journal,(2015); 1: 447-51.

[24]. Howard V. A Comparison of Educational Strategies for the Acquisition of Medical-Surgical Nursing Knowledge and Critical Thinking Skills: Human Patient Simulator vs. the Interactive Case Study Approach. (2012) Ed D thesis, University of Pittsburgh, Pittsburgh, PA.

[25]. Benner, P., Sutphen, M., Leonard, V. \& Day, L. Educating nurses: A call for radical transformation. (2011). Washington, DC: Carnegie Foundation.

[26]. Calaluce L, Kallen E, Fathi-Azar E,Ghiasvandian S,Akbarzadeh B. The effect of simulation teaching on baccalaureate nursing students' self-confidence related to peripheral venous catheterization in children: a randomized trial.Journal of Caring Sciences,(2013); 2(2): 157-64

[27]. Beaubien J., \& Baker D. The use of simulation for training teamwork skills in health care: How low can you go? Quality and safety in health care, (2014). 13:(S1), i51-6.

[28]. Medley, C. F., \& Horne, C. Using simulation technology for undergraduate nursing education. Journal of Nursing Education,(2015); 44(1): 31-4.

[29]. Nevin M, Neill S and Mulkerrins N. Measuring student perceptions of clinical competence. Journal of Nurse Education, (2014);42(12):548-54.

[30]. Bultas MHassler L, Ercor N, and HaasF .Enhancing the pediatric undergraduate nursing curriculum through simulation.Journal of Pediatric Nurse. 2013; 26(3):224-9.

[31]. Kaddoura, M. New graduate nurses' perceptions of the effects of clinical simulation on their critical thinking, learning, and confidence. Journal of Continuing Education in Nursing,(2014); 41(11):506-16.

[32]. Clark C, Springer P. Nurse residents' first hand accounts on transition to practice. Nurs Outlook. (2012); 60: E2-8. Available @ http://dx.doi.org/10.1016/j.outlook.2011.08.003

[33]. Kim, Y., Chun, N., Lee, E. H., Cho, I. S., Ahn, S., Kim, J., Application of High Fidelity Simulation for Acquisitions of Nursing Skills: Nursing Students' Perspective.International Journal for Innovation Education and Research.(2015);(3):178-93

[34]. The Joint Commission. National patient safety goals: Hospital. (2011). Available @ http://www.jointcommission.org/NR/rdonlyres/D619D05C-A682-47CB-874A DE16D21CE24/0/HAP_NPSG_Outline.pdf

[35]. Castanelli, D.J. The rise of simulation in technical skills teaching and the implications for training novices in anaesthesia.Anaesthesia Intensive Care, (2010); 37(6): 903-10. 